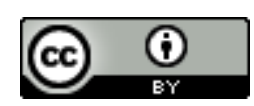

Esta obra está sob o direito de Licença Creative Commons Atribuição 4.0 Internacional.

\title{
ALFABETIZAÇÃO DE JOVENS E ADULTOS: Concepções e práticas pedagógicas
}

Silvania Marques de Almeida ${ }^{1}$ Maria José Soares Ribeiro2

\begin{abstract}
RESUMO
O presente artigo resulta em uma revisão sistemática integrativa sobre concepções e práticas pedagógicas desenvolvidas na Educação de Jovens e Adultos (EJA) ao longo da trajetória dessa modalidade de ensino no Brasil, com destaque para o novo olhar impresso pelas teorias e métodos do educador Paulo Freire. A fundamentação teórica evidencia o perfil do docente no século XXI; as contribuições das tecnologias como recurso pedagógico para melhoria do processo de ensino e aprendizagem; e as concepções teóricas e legislação vigente sobre a alfabetização de jovens e adultos no Brasil. O objetivo desta pesquisa foi avaliar resultados apontados em estudos realizados sobre o processo educacional desenvolvido pela EJA ao longo dos últimos quatro anos. Como metodologia optou-se por desenvolver uma revisão sistemática integrativa por meio de um levantamento de estudos publicados em plataformas digitais no recorte temporal dos últimos quatro anos. Constata-se que existem questões que impactam nos sujeitos envolvidos na EJA e que provocam evasão e/ou desmotivação tanto no aluno, como o cansaço, carga horária de trabalho e aulas descontextualizadas de suas realidades, quanto no professor que normalmente não possui uma formação específica para EJA. Conclui-se pela urgência na implementação de políticas públicas que promovam a eficiência na EJA, considerando especialmente a Andragogia e a formação acadêmica de professores para que se estabeleça uma aprendizagem significativa. Jovens e adultos que resolvem voltar à escola para concluir a educação básica normalmente anseiam avançar para o ensino superior, melhores oportunidades no mercado de trabalho e um resgate de cidadania.
\end{abstract}

Palavras-chave: EJA. Andragogia. Cidadania. Aprendizagem significativa. Tecnologias.

\footnotetext{
${ }^{1}$ Silvania.marques.aa@hotmail.com

${ }^{2}$ mariajosebeu7@gmail.com
} 


\section{INTRODUÇÃO}

O processo educacional de jovens e adultos (EJA) no Brasil teve suas primeiras iniciativas com a chegada dos padres jesuítas, que ao catequizarem os índios lhes ensinavam a ler e a escrever a língua portuguesa.

Contudo, até meados da década de 1950, as pessoas adultas analfabetas eram rotuladas como ignorantes e representavam um risco de subversão, concepções reforçadas pela ideologia da criminalização da pobreza, que além de estigmatizar essas pessoas, excluam-nos e negavam-lhes seus direitos.

Em 1958, durante o $2^{\circ}$ Congresso Nacional de Educação de Adultos, a EJA passou a ser discutida inspiradas nas ideais do educador Paulo Freire que se mostravam sensíveis às pessoas analfabetas que não tiveram a oportunidade de frequentar uma escola em idade regular devido a diferentes razões, a exemplo da necessidade de trabalhar para ajudar no sustento da família. A partir desse contexto, a EJA passou a ser concebida com novas propostas pedagógicas por meio de um currículo programático baseado na realidade dos alunos e como meio transformador social.

Essa nova realidade foi se destrinchando em outras propostas afins ao EJA, e na contemporaneidade tem como expressões o novo perfil do professor e o uso de tecnologia da comunicação e informação digitais.

O processo educacional é algo dinâmico e por isso passa por transformações significativas em suas didática e metodologia.

\section{MÉTODOLOGIA}

Trata-se de uma revisão sistemática integrativa por meio de uma revisão de literatura sobre o tema proposto, baseado num levantamento de artigos científicos e trabalhos monográficos disponíveis em plataformas digitais como: Scielo e Google Acadêmico, e em revistas especializadas como: Revista do Centro de Ciências da Educação; Revista Brasileira de Educação de Jovens e Adultos; Educationis; e Educação \& Realidade.

A seleção das referências deu-se pelos termos chaves: EJA; ensino; aprendizagem; políticas públicas; concepções pedagógicas. Foram levantadas referências publicadas no ano de 2020, em que são evidenciadas análises e pesquisas sobre o tema proposto nesta dissertação.

A referida pesquisa propõe-se a apresentar os resultados apontados nos estudos referentes às ações desenvolvidas para a EJA, identificando concepções pedagógicas e visões sobre políticas públicas inerentes a esta modalidade de ensino.

\section{RESULTADOS E DISCUSSÕES}

Diante dos estudos levantados, fazse a apresentação dos resultados neles apresentados em torno de concepções e práticas pedagógicas, bem como de políticas públicas voltadas para a EJA. Entende-se como resultados as conclusões e/ou considerações finais de cada estudo, contudo, cada estudo será referenciado pelo objetivo proposto. Tais resultados serão discutidos individualmente e ao final será feita uma breve consideração sobre os resultados apontados nos estudos.

Apresentação dos resultados segundo o Quadro 1. 
Quadro 1

Estudos selecionados

\begin{tabular}{|c|c|c|c|c|c|}
\hline $\mathbf{N}$ & TÍTULO & ANO & AUTORES & $\begin{array}{l}\text { PALAVRAS- } \\
\text { CHAVE }\end{array}$ & $\begin{array}{c}\text { TIPO DE } \\
\text { PESQUISA }\end{array}$ \\
\hline $\mathbf{1}$ & $\begin{array}{c}\text { EJA - Educação de Jovens } \\
\text { e Adultos como } \\
\text { possibilidade de } \\
\text { transformação social }\end{array}$ & 2020 & ALVES & $\begin{array}{c}\text { EJA. Educação. } \\
\text { Transformação Social. }\end{array}$ & $\begin{array}{l}\text { Revisão de } \\
\text { literatura }\end{array}$ \\
\hline 2 & $\begin{array}{c}\text { A educação à distância e } \\
\text { o ensino de jovens e } \\
\text { adultos }\end{array}$ & 2020 & BEZERRA & $\begin{array}{l}\text { Educação à distância. } \\
\text { Educação de Jovens e } \\
\text { Adultos. Ensino. }\end{array}$ & $\begin{array}{c}\text { Pesquisa } \\
\text { bibliográfica }\end{array}$ \\
\hline 3 & $\begin{array}{c}\text { Alfabetização e } \\
\text { letramento na educação } \\
\text { de jovens e adultos: } \\
\text { mapeamento da produção } \\
\text { acadêmica em periódicos } \\
\text { no Brasil }\end{array}$ & 2020 & $\begin{array}{c}\text { FREITAS et } \\
\text { al. }\end{array}$ & $\begin{array}{c}\text { Alfabetização. } \\
\text { Letramento. Educação } \\
\text { de Jovens e Adultos. } \\
\text { Pesquisas na } \\
\text { Educação. }\end{array}$ & $\begin{array}{c}\text { Pesquisa } \\
\text { bibliográfica }\end{array}$ \\
\hline 4 & $\begin{array}{l}\text { Políticas de Certificação } \\
\text { para Jovens e Adultos - o } \\
\text { caso dos Exames de } \\
\text { Madureza }\end{array}$ & 2020 & $\begin{array}{l}\text { MACHADO; } \\
\text { LAGO }\end{array}$ & $\begin{array}{l}\text { Exame de Madureza; } \\
\text { Certificação; } \\
\text { Educação de Jovens e } \\
\text { Adultos }\end{array}$ & $\begin{array}{c}\text { Pesquisa } \\
\text { bibliográfica }\end{array}$ \\
\hline 5 & $\begin{array}{l}\text { A avaliação como } \\
\text { instrumento eficaz para a } \\
\text { qualidade do processo de } \\
\text { alfabetização de jovens e } \\
\text { adultos }\end{array}$ & 2020 & PEREIRA & $\begin{array}{c}\text { Avaliação. Qualidade } \\
\text { de Ensino. Jovens e } \\
\text { Adultos. }\end{array}$ & $\begin{array}{c}\text { Pesquisa } \\
\text { bibliográfica }\end{array}$ \\
\hline 6 & $\begin{array}{l}\text { Os Sujeitos da EJA nas } \\
\text { pesquisas em Educação } \\
\text { de Jovens e Adultos }\end{array}$ & 2020 & $\begin{array}{l}\text { SANTOS; } \\
\text { SILVA }\end{array}$ & $\begin{array}{c}\text { Educação de Jovens e } \\
\text { Adultos. Sujeitos da } \\
\text { Educação. } \\
\text { Diversidade. }\end{array}$ & $\begin{array}{c}\text { Pesquisa } \\
\text { bibliográfica }\end{array}$ \\
\hline
\end{tabular}

Fonte: Autoria própria 


\section{DISCUSSÃO}

Alves (2020) tem Paulo Freire como referência ao refletir sobre a importância da educação para formar cidadãos atuantes e críticos sobre os acontecimentos sociais, históricos e políticos; sobre fatores relacionados à evasão escolar, com destaque para as políticas públicas de Educação no país, o alto índice de analfabetismo e o importante papel de educadores diante do desafio que é o ensino de jovens e adultos trabalhadores. A necessidade de uma educação que contemple a realidade dos alunos da EJA não é um mero atendimento a uma condição socialmente estabelecida que levou esses sujeitos a não frequentar a escola em idade regular, e muito menos um ato compensatório, pois, o direito à educação não é uma recompensa, é uma necessidade básica. Esses sujeitos precisam ser vistos em suas potencialidades e devem ter a oportunidade de se tornarem críticos e autônomos em seus protagonismos. Bezerra (2020) destaca o Ensino à Distância (EAD) como um possível instrumento de ensino e aprendizagem para o processo educacional brasileiro, propiciando uma expressiva inclusão de alunos no processo de alfabetização e escolarização.

A EAD pode ser uma solução para jovens e adultos que desejam retornar à escola com pretensão de concluir a educação básica, sob justificativas como não possuírem meios de frequentar aulas presenciais ou porque simplesmente se identificam com aulas remotas. $\mathrm{O}$ importante é que haja interesse e que esta ferramenta digital seja oportunizada (BEZERRA, 2020).

Freitas et al. (2020) mapearam as temáticas, categorias, objetos de análise e autores principais que fundamentam os estudos sobre alfabetização e letramento na EJA por meio de pesquisas publicadas em periódicos. Constata-se que as produções apresentam como base empírica contextos formais de educação-formação e a relação entre alfabetização e letramento, evidenciando a complexidade inerente aos modos como estes termos estão sendo ressignificados (FREITAS et al., 2020).

Buscando fatos históricos para compreender a validação da EJA, Machado e Lago (2020) apresentaram resgataram a história dos Exames de Madureza no Estado de Goiás, para compor o acervo de documentação e memória da Educação de Jovens e Adultos (EJA) deste Estado. Esse resgate histórico possibilita avaliar o processo evolutivo da EJA no Brasil desde século XX a partir de transformações socioculturais que promoveram melhores perspectivas para os alunos, motivaram mulheres adultas a se alfabetizarem e despertaram para discussões em torno de uma concepção para formação pedagógica e crítica, apesar de tal concepção permanecer mais no campo das ideias do que na prática.

Tão importante quanto ofertar a EJA é avaliar sua eficiência como modalidade de ensino. Em razão disso, Pereira (2020) considerou a avaliação como uma das ferramentas indispensáveis, haja vista o aluno ter ciência de como está a sua aprendizagem, da mesma forma que o professor deve estar atento ao seu próprio planejamento. A questão social aparece também na avaliação, ou seja, a formação deve ser pedagógica e ter este olhar de criticidade social, despertando para valores de cidadania, e assim deve ser o olhar avaliativo do professor.

Santos e Silva (2020) defendem a necessidade de se conhecer o sujeito da 
EJA para poder desenvolver políticas públicas que atendam as demandas para o ensino, pois, mesmo havendo produções cientificas sobre esta modalidade de ensino há uma carência sobre particularidades relacionadas às pessoas que se alfabetizam na idade adulta. Conhecer a realidade dos alunos é fundamental para a formação dos professores e para a contextualização de conteúdo.

Diante dos estudos analisados nesta revisão sistemática integrativa ficou evidente o quanto a questão social é definidora para a proposta de políticas públicas voltadas para a EJA. O processo ensino/aprendizagem deve priorizar conteúdos contextualizados com a realidade do aluno a fim de despertar no mesmo uma identificação que o motivará a permanecer estudando e ao mesmo tempo em que aprende os ensinamentos pedagógicos, seu cognitivo precisa ser estimulado para discutir e argumentar positivamente sua inserção na sociedade $\mathrm{e}$ como pode contribuir para uma sociedade com senso crítico.

Verificou-se também fatores que propiciam a evasão escolar na EJA, normalmente motivada pelo cansaço dos alunos que emendam trabalho com aulas ou pelo desestímulo em sala de aula com a proposta pedagógica apresentada. Isto leva a uma reflexão sobre a formação profissional de professores em razão de uma especialização voltada para a EJA que tenha como uma de suas bases a Andragogia.

O analfabetismo é um problema estrutural no Brasil e isto ainda posiciona a EJA como um ensino voltado a pessoas com pouca capacidade de aprendizagem, ou seja, perpetua-se um estigma em torno dos sujeitos nessa modalidade de ensino, quando na verdade são pessoas que por diferentes razões (exceto incapacidade intelectual) abandonaram os estudos em idade regular.

Preocupa o atual posicionamento da gestão da educação nacional, que sinaliza para uma quebra de paradigmas em torno da visibilidade da EJA erguida em governos anteriores através de leis e programas específicos. Ideais e teorias de Paulo Freire não são acolhidas no governo atual por desacreditar do papel críticosocial da escola.

Em resposta ao problema levantado, avalia-se que não se tem meios para constatar a eficácia da educação de jovens e adultos em meio ao processo evolutivo educacional no Brasil por que não há uma política pública voltada à mensuração de resultados para essa modalidade, no máximo computa-se dados numéricos sobre desistências e conclusões da educação básica. Nos artigos científicos e trabalhos monográficos avaliados fica evidente essa pendência quando há uma insistência no desenvolvimento de políticas públicas eficazes para a EJA, especialmente na formação do educador e nas metodologias ofertadas aos alunos.

\section{CONCLUSÕES}

No processo histórico da EJA verifica-se a descontinuidade e a fragmentação das políticas públicas o que reflete na sala de aula e compromete a democratização do acesso ao conhecimento institucionalizado e sistematizado. Investimento irrisório, descontinuidade das políticas educacionais, dificuldade de acesso e permanência na escola e a formação de professores são fatores que precisam ser reavaliados para a promoção de uma educação contextualizada e que 
compreenda a realidade sócio-histórica dos alunos, visando a equidade social.

Os artigos científicos e trabalhos de conclusão de curso analisados na revisão sistemática integrativa revelam a importância da EJA para o resgate da cidadania dos alunos, haja vista que habilidades como leitura e escrita são imprescindíveis no contexto social em que a alfabetização vai além de componentes curriculares e transborda para discussões sociais.

Contudo, ainda é irrisória a produção acadêmica sobre a EJA e em meio as que foram objeto de estudo nesta dissertação, há carência de estudos aprofundados sobre a realidade dos jovens e adultos que decidem retornar ao ambiente escolar. Conhecer essa realidade é imprescindível para a definição e efetividade de políticas públicas voltadas para a inserção educacional e social dessas pessoas que resolvem recomeçar a estudar.

\section{REFERÊNCIAS}

ALVES, Marlene Rodrigues S. EJAEducação de Jovens e Adultos como Possibilidade de Transformação Social. 2020. 45 f. Trabalho de Conclusão de Curso (Graduação em Letras - Espanhol e Português como Línguas Estrangeiras) Instituto Latino-Americano de Arte, Cultura e História da Universidade Federal da Integração Latino-Americana, Foz do Iguaçu-PR, 2020.

BEZERRA, Thaynara. A educação à distância e o ensino de jovens e adultos. Revista Científica Semana Acadêmica. Fortaleza, ano MMXX, Nº 000195, 04/06/2020. Disponível em: https://semanaacademica.com.br/artigo/ educacao-distancia-e-o-ensino-de- jovens-e-adultos. Acessado em: 10 fev. 2021.

FREITAS, Marinaide Lima de Queiroz; et al. Alfabetização e letramento na educação de jovens e adultos: mapeamento da produção acadêmica em periódicos no Brasil. Revista do Centro de Ciências da Educação, Volume 38, n. 1 p. 01-18, jan./mar. 2020.

MACHADO, Maria Margarida; LAGO, Stephany Nascimento. Políticas de Certificação para Jovens e Adultos - o caso dos Exames de. Rev. Bras. de Educ. de Jov. e Adultos, vol. 7, 2020.

PEREIRA, I. A... A avaliação como instrumento eficaz para a qualidade do processo de alfabetização de jovens e adultos. Educationis, v.8, n.1, p.37-52, 2020

SANTOS, Pollyana dos; SILVA, Gabriela da. Os Sujeitos da EJA nas Pesquisas em Educação de Jovens e Adultos. Educação \& Realidade, Porto Alegre, v. 45, n. 2, e96660, 2020. 